\title{
O PAPEL DO MINISTÉRIO PÚBLICO NA EDUCAÇÃO AMBIENTAL POR MEIO DO TERMO DE AJUSTAMENTO DE CONDUTA
}

\author{
Pablo da Costa Ribeiro ${ }^{1}$ \\ Luiz Ernani Bonesso de Araujo ${ }^{2}$
}

\begin{abstract}
RESUMO
Os graves desequilíbrios verificados na natureza pela ação do homem são motivo de forte preocupação para ambientalistas do mundo todo. Para combater os males que assolam o ambiente surgiu como proposta pedagógica a Educação Ambiental cujo objetivo é a disseminação do conhecimento sobre o ambiente. Em uma perspectiva interdisciplinar, a Educação Ambiental precisa contar com aliados de outros campos do conhecimento para auxiliá-la nessa árdua missão de conscientização das pessoas. E esse aliado pode ser o órgão do Ministério Público, defensor da ordem jurídica, do regime democrático e dos interesses individuais indisponíveis. A interação da Educação Ambiental com o Ministério Público, a partir da educação, pode se dar por meio do termo de ajustamento de conduta (TAC) que vem a servir como proposta sócio-educacional efetiva para combater os desmandos provocados pelo homem na natureza.
\end{abstract}

Palavras-chave: Educação Ambiental, Ecopedagogia, Ministério Público, Termo de Ajustamento de Conduta.

\section{INTRODUÇÃO}

Nos dias atuais, cada vez mais a sociedade, impulsionada por uma nova consciência, vem se preocupando com a questão ambiental, ante os graves desequilíbrios verificados na natureza.

A Educação Ambiental, a partir dessa realidade, apresenta-se como uma das mais importantes ferramentas, senão a mais importante, para diminuir os impactos causados pelas alterações climáticas e ambientais. A disciplina pertence ao ramo da educação cujo objetivo é a disseminação do conhecimento sobre o ambiente, com o fito de auxiliar na preservação e na utilização sustentável dos recursos naturais.

Com efeito, os problemas de poluição e degradação que o mundo enfrenta, incentivados por um consumismo desenfreado, especialmente em países emergentes, tornam o quadro ambiental ainda mais delicado. Enquanto boa parte da população mundial fica à margem dos benefícios do capitalismo, outras poucas usufruem de toda a

\footnotetext{
${ }^{1}$ Especialista em Educação Ambiental pela UFSM, funcionário público estadual, pablorib@terra.com.br

2 Docente do Curso de Especialização em Educação Ambiental e do Departamento de Direito da UFSM, luiz.bonesso@gmail.com
} 
riqueza, estimuladas pelos ideais liberais de acumulação de valores. Tudo isso dentro de uma perspectiva real de exaustão dos recursos naturais.

Nesse sentido, trata-se a Educação Ambiental de um processo pedagógico participativo permanente, que visa incutir nas pessoas uma consciência crítica sobre a problemática ambiental, estendendo à sociedade a capacidade de captar a gênese e a evolução de problemas relacionados ao meio ambiente.

Esse artigo propõe-se a apresentar a instituição pública Ministério Público como aliado de uma nova proposta pedagógico educacional. Na sua missão constitucional de fazer a defesa da ordem jurídica, do regime democrático e principalmente, dos interesses sociais e direitos coletivos e individuais indisponíveis, caso do meio ambiente, o Ministério Público pode participar também do processo educacional brasileiro através do chamado Termo de Ajustamento de Conduta ou Compromisso de Ajustamento de Conduta (TAC), que é um instrumento legal de atuação extrajudicial em relação ao qual o órgão ministerial realizará, na verdadeira acepção da palavra, "a educação das pessoas" corrigindo e prevenindo práticas atentatórias ao meio ambiente.

\section{A Educação Ambiental}

A partir do advento da Constituição Federal de 1988, foi concebida uma proteção ampla ao meio ambiente, bem de uso comum do povo, pertencente a todos indistintamente, uma vez que definido como direito difuso. Alguns anos depois foi prevista expressamente a disciplina da Educação Ambiental, com a determinação de que o Poder Público viesse a promover a matéria em todos os níveis de ensino, bem como a conscientização pública para a preservação do meio ambiente. No mesmo norte, a educação ficou definida como um direito social de todos e dever do Estado e da família (artigos $6^{\circ}$ e 205) (ARAUJO; TYBUSCH; SILVA, 2007).

Foi com a edição da Lei n. ${ }^{\circ}$ 9.795/99 que a Educação Ambiental passou a gozar de contornos oficiais no Brasil. Essa legislação instituiu a Política Nacional de Educação Ambiental que materializou em seu texto as recomendações nacionais e internacionais conhecidas até então, institucionalizando os princípios básicos e objetivos da Educação Ambiental, transformando-a em objeto de política pública (BRASIL, 1999). 


\section{A Política Nacional de Educação Ambiental e a importância de um tratamento educacional interdisciplinar}

A Lei n. ${ }^{\circ}$ 9.795/99 constituiu-se em um marco decisivo para a implantação da Política Nacional de Educação Ambiental no país. Segundo a referida legislação, tal proposta pedagógica consiste em processos por meio dos quais o indivíduo e a coletividade constroem valores sociais, conhecimentos, habilidades, atitudes e competências voltadas para a conservação do meio ambiente, essencial à sadia qualidade de vida e sua sustentabilidade. Ademais, traduz-se num componente essencial e permanente da educação nacional, necessitando estar presente, de forma articulada, em todos os níveis e modalidades do processo educativo, em caráter formal e nãoformal (BRASIL, 1999).

Mas o que se compreende por educação formal e não-formal? Pois bem, entende-se por educação formal aquela desenvolvida nos bancos escolares e que se encontra inserida nos currículos das instituições públicas e privadas, englobando a educação básica, superior, especial, profissional e de jovens e adultos. Nesse sentido, a Educação Ambiental deverá consistir numa prática educativa integrada e permanente, mas que não poderá ser implantada como uma disciplina específica nos currículos escolares, exceto nos cursos de pós-graduação, extensão e nas áreas voltadas ao aspecto metodológico da Educação Ambiental.

Ocorre que a proibição legal existente quanto à implantação de uma disciplina específica de Educação Ambiental nos currículos escolares, denota coerência e adequação com todo o conteúdo disciplinado na presente Lei, de vez que se deseja justamente modificar a maneira tradicional fragmentada, compartimentada do processo educativo. Com esse objetivo pretende-se integrar a temática ambiental nos conteúdos de português, matemática, física, química, biologia, dentre outras disciplinas curriculares, assim como em todos os anos do ensino formal, em clara alusão ao conceito interdisciplinar do filósofo Edgar Morin (MORIN, 2002).

A educação interdisciplinar rompe com paradigmas disciplinares fechados, fazendo nascer uma educação totalmente interrelacionada. A partir do paradigma da complexidade, o termo Educação Ambiental pode apresentar possibilidades 
emancipatórias e transformadoras. Esta é uma perspectiva bastante desafiadora, pois admite incertezas, espaços não-fixos e processos dinâmicos.

Já a Educação Ambiental não-formal são ações voltadas à participação da sociedade sobre as questões ambientais que afetam o cotidiano das pessoas. Embora aqui também tenha o Poder Público a tarefa de incentivar a prática, é nesse espaço que a comunidade em geral irá participar e responsabilizar-se pela transmissão de informações e conhecimentos acerca de assuntos envolvendo a preservação e proteção do meio ambiente.

Assim, a efetivação de políticas para ações na área da Educação Ambiental está totalmente atrelada a uma nova racionalidade, caracterizada por uma postura ética de responsabilidade entre as gerações atuais e futuras e de atitudes dos atores sociais contemporâneos. É aí que se insere o importante papel que as práticas pedagógicas da Educação Ambiental podem desempenhar junto à sociedade.

Os saberes para a Educação Ambiental, por assim dizer, devem estar relacionados a espaços convencionais, estabelecidos em um território, quanto em espaços flexíveis e virtuais (MORIN, 2002).

Nessa perspectiva, vão se configurando "grupos" de aprendizagem que é quando uma comunidade humana organizada constrói um projeto educativo e cultural próprio, para instruir a si própria, suas crianças, jovens e adultos, graças a um esforço concentrado, cooperativo e solidário, baseado em um diagnóstico não apenas de suas carências, mas, sobretudo, de suas forças para superar essas carências (MORIN, 2002).

Mostra-se importante, com base nessa visão multidimensional e interdisciplinar, resgatar a aproximação das pessoas às realidades do meio ambiente, seus principais problemas, e a forma como podem ser tratadas e superadas às dificuldades ambientais. Integrar a comunidade é trazê-la para uma compreensão holística, partindo do todo para cada um dos problemas relacionados com a Educação Ambiental.

Por tudo isso o termo Educação Ambiental não poderá receber caracterização diversa daquilo que se conhece acerca do pensamento complexo e interdisciplinar, porque apreender a complexidade ambiental implica num processo de desconstrução e reconstrução do pensamento. Este desconstruir-reconstruir sugere uma reforma em todo o modo de ver, pensar e compreender o mundo e, muito mais do que isso, aponta para uma reorganização do saber até aqui estruturado, através de uma contínua busca de 
articulação e interdependência entre estes saberes que formarão o conceito de Educação Ambiental (físico, biológico e químico) (MORIN, 1991).

De acordo com o pensamento complexo e interdisciplinar, o homem deve ter a preocupação de conservar o ecossistema, pois integra o mesmo. A consideração do objeto de estudo como sistema seria o primeiro dos princípios básicos do paradigma da complexidade, como novo marco interpretativo e para o estudo dos fenômenos, em especial, os que afetam o meio ambiente (SILVA; CANTARELLI; NIEDERAUER, 2007).

Sob esse enfoque, impulsionar a educação ambiental é criar uma profunda reflexão sobre as práticas existentes na utilização dos recursos naturais, na perspectiva de rever a relação do homem com a natureza, apartando-se de uma visão meramente conservacionista (ARAUJO; TYBUSCH; SILVA, 2007).

Para Gadotti (2000), a Educação Ambiental deve ir além do conservacionismo. Trata-se de conceber-se uma mudança radical de mentalidade no tocante a temas como qualidade de vida, que está intimamente ligada ao tipo de convivência que se tem com a natureza e que implica numa tomada de valores e ações em prol de sua manutenção.

A partir da compreensão do conceito de Educação Ambiental, torna-se necessário emprestar maior efetividade a ele, realizando-se uma completa mudança de paradigma, onde se deve valorizar o todo ao invés das partes, o complexo ao reducionista, o total ao específico, religando os saberes (MORIN, 1991). E para esse intento a interdisciplinaridade, cumpre um papel fundamental.

Portanto, a Educação Ambiental não pode prescindir dessa visão complexa e interdisciplinar, voltada à integração com a multiplicidade de perspectivas que advêm das diversas e variadas áreas do conhecimento, porque delas faz parte e ao mesmo tempo as abrange. O enfoque da complexidade se abre ao intercâmbio, ao entrelaçamento de conceitos, visões, pressupostos, verdades. A realidade e os problemas ambientais são cada vez mais abrangentes, globais, planetários, e, por isso, estão a requerer uma visão interdisciplinar, multidimensional para encará-los sob uma ótica redimensionada pela ética da solidariedade e por uma "ciência com consciência".

É nesse prisma que se deve colocar a Educação Ambiental, considerada uma abordagem complexa. Por isso, a opção em integrar a temática da ciência do direito, da 
conduta, e a do ente legitimado, que firma o compromisso -, mas não é propriamente transação porque não há concessões recíprocas e nem poderia haver em se tratando de bem ambiental cujo interesse é indisponível (GONÇALVES, 2006).

O termo de compromisso tem por fim encerrar o litígio, evitando a ação civil pública. Nele, só o causador do dano ambiental assume a responsabilidade. Ao celebrá-lo, o transgressor reconhece a obrigação de tomar providências, ajustando a sua conduta de acordo com as necessidades dos interesses transindividuais (sem que haja qualquer concessão por parte do ente legitimado, no caso deste estudo o Ministério Público). Trata-se quase de um reconhecimento da postulação do ente legitimado, antes mesmo que ela seja formulada judicialmente, e com a finalidade de evitar o ajuizamento da ação. (GONÇALVES, 2006).

O termo de compromisso de ajustamento é sempre celebrado extrajudicialmente e, para que adquira força de título executivo, basta que seja firmado pelo ente legitimado e pelos causadores do dano ambiental, sendo desnecessário que o seja por duas testemunhas. Deve constar do termo de ajustamento de conduta o prazo para o cumprimento das obrigações e a sanção, para o descumprimento, com as medidas coercitivas que poderão ser impostas em caso de omissão, como, por exemplo, a multa diária (astreintes). É preciso que o termo indique, com precisão, a obrigação a ser cumprida, que deve ser certa e determinada.

Em regra, o termo conterá uma obrigação de fazer ou não fazer (por exemplo, a de implantar, em determinado prazo, filtros antipoluentes em indústria de celulose ou absterse o causador do dano de realizar queimadas em determinada área de proteção permanente, contígua à área de lavoura), mas nada impede que contenha outras espécies de obrigação, como a de entrega de coisa ou de pagamento em dinheiro (por exemplo, a de um pecuarista que desmata pequena área de preservação permanente, de entregar para plantio árvores nativas que acabou destruindo com sua ação).

Para que o termo de compromisso adquira força de título executivo extrajudicial, nada mais é preciso do que o cumprimento das exigências do $\S 6^{\circ}$ do artigo $5^{\circ}$ da Lei de Ação Civil Pública. Não é condição de eficácia a sua homologação perante o Conselho Superior do Ministério Público. Mas se, por força do termo de compromisso, for arquivado inquérito civil aberto pelo Ministério Público, para apuração dos fatos, este ato estará sujeito à homologação do Conselho Superior do órgão. 


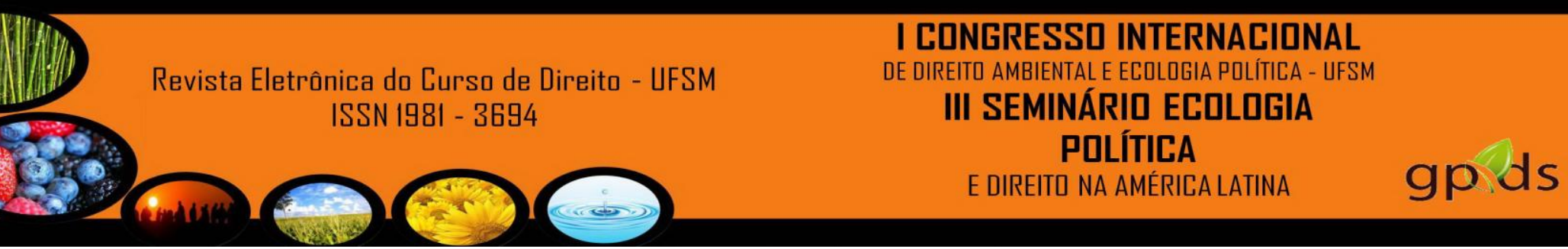

\section{O Termo de Ajustamento de Conduta como medida sócio educacional}

Com efeito, existe um grande distanciamento entre a consciência ecológica almejada pela Educação Ambiental e aquela que se busca aprimorar, de fato, na sociedade, ao mesmo tempo em que pode haver obstáculos impedindo a aproximação da sociedade com o Ministério Público, órgão incumbido constitucionalmente de representála na esfera judicial. Os operadores do direito, especialmente os dedicados à causa ministerial, têm a tarefa de unir os conceitos de Educação Ambiental e Ministério Público, tornando o órgão mais conhecido e mais atuante, para deles retirar o máximo em proteção ao meio ambiente. Aliás, diga-se de passagem, são dois conceitos que se mostram absolutamente compatíveis e adequados na ordem social e que, por isso, devem caminhar juntos.

De sua parte, o Ministério Público é o órgão responsável, por excelência na esfera jurídica, para defender o meio ambiente, haja vista que a Constituição Federal afirma possuir ele o dever de zelar pelo interesse coletivo. Para tanto, o órgão ministerial é dotado de instrumentos de atuação que lhe possibilita realizar com sucesso as prerrogativas constitucionais que lhe são conferidas.

Esse é o entendimento de Loureiro; Layarargues e Castro (2005, p. 94):

(...) Em conclusão, o quinto aspecto a ser destacado, que constitui novidade para a população, refere-se ao direito constitucional de cada cidadão de reivindicar seu direito a um ambiente sadio ecologicamente equilibrado na justiça, por intermédio do Ministério Público. Com a Constituição de 1988, o Ministério Público alcançou grande relevância no cenário nacional. Ele é definido no art.127 como instituição permanente e essencial à função jurisdicional do Estado, cabendo-lhe a defesa da ordem jurídica, do regime democrático e dos interesses sociais e individuais, sendo especificadas no art. 129 suas funções. O Ministério Público é uma instituição independente, com autonomia administrativa e financeira, o que se revela essencial para a defesa da sociedade, pois essa tarefa pode, em certas circunstâncias, significar a oposição a decisões dos poderes Executivo, Legislativo ou do próprio Judiciário. Por intermédio do Ministério Público, pode-se promover o inquérito civil e a ação pública para a proteção dos direitos constitucionais, do 




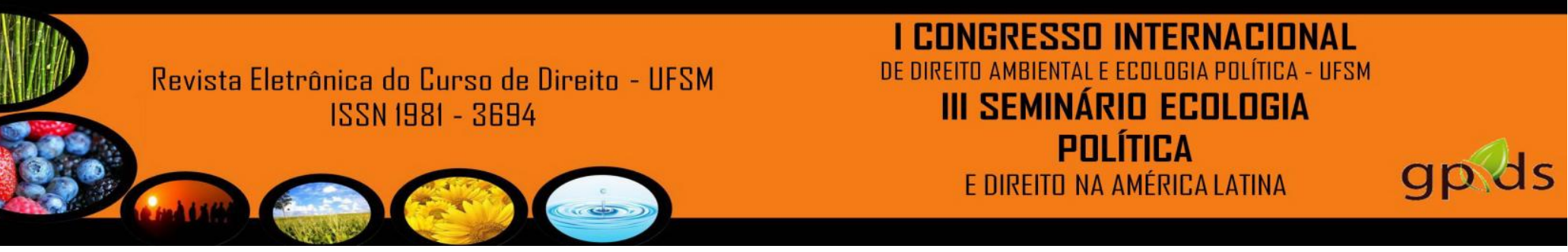

STEIGLEDER, Annelise Monteiro; CAPELLI, Sílvia. Direito Ambiental. Porto Alegre, RS: Verbo Jurídico, 2004.

ARAUJO, Luiz Ernani Bonesso de; TYBUSCH, Jerônimo Siqueira de; SILVA, Andressa Correa da. Educação ambiental, mídia e cidadania.In: GORCZEVSKI, Clóvis (org.) Direitos Humanos Educação e Cidadania. Porto Alegre, RS: Ed. da UFRGS, 2007.

BRASIL. Lei $\mathbf{n}^{\mathbf{0}}$ 7.347/85: promulgada em 24 de julho de 1985. Disponível em: <http://www4.planalto.gov.br/legislação>. Acesso em: 14 de julho de 2012.

Lei $\mathbf{n}^{\circ}$ 8.078/90: promulgada em 11 de setembro de 1990. Disponível em: <http://www4.planalto.gov.br/legislação>. Acesso em: 14 de julho de 2012.

Lei no 9.795/99: promulgada em 27 de julho de 2012. Disponível em:

<http://www.planalto.gov.br/ccivil_03/Leis/L9795.htm>. Acesso em: 14 de julho de 2011.

CAPRA, Fritjof. A Teia da Vida: uma nova compreensão científica dos sistemas vivos. Trad. Newton R. Eichemberg. São Paulo, SP: Cultrix, 2004.

FREIRE, Paulo. Educação como prática da liberdade. Rio de Janeiro: Paz e Terra, 1967.

FINK, Daniel Roberto. Alternativas à ação civil pública ambiental (reflexões sobre as vantagens do termo de ajustamento de conduta) [2000]. In: MILARÉ, Édis. Direito do Ambiente: a gestão ambiental em foco: doutrina, jurisprudência, glossário. 6. ed. rev. atual. ampl. São Paulo: Revista dos Tribunais, 2009.

GADOTTI, Moacir. Perspectivas atuais da educação. Porto Alegre: Artes Médicas, 2000.

GONÇALVES, Marcus Vinícius Rios. Tutela de interesses difusos e coletivos. São Paulo: Saraiva, 2006.

GUIMARÃES, Mauro. A formação de educadores ambientais. Campinas, SP: Papirus, 2004.

LEFF. Henrique. Pensar a Complexidade Ambiental. Trad. Eliete Wolff. São Paulo: Cortez, 2003.

LOUREIRO, Carlos Frederico Bernardo; LAYARARGUES, Philippe Pomier;

CASTRO; Ronaldo de Souza. Educação Ambiental: repensando o espaço da cidadania. 3. ed. São Paulo: Cortez, 2005.

MARCHESAN, Ana Maria Moreira; STEIGLEDER, Annelise Monteiro; CAPELLI, Sílvia. Direito Ambiental. Porto Alegre; Verbo Jurídico, 2004. 


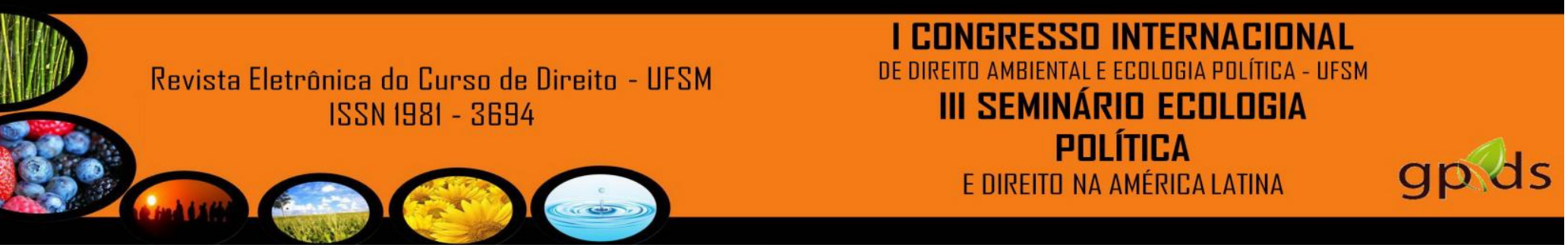

MORIN, Edgar. Introdução ao pensamento complexo. 1. ed. Tradução Dulce Matos Lisboa: Instituto Piaget, 1991.

A Religação dos Saberes: o desafio do século XXI. 2. ed. Tradução de Flávia Nascimento. Rio de Janeiro: Bertrand Brasil, 2002.

RUSCHEINSKY, Aloísio; COSTA, Adriane Lobo. A Educação Ambiental a partir de Paulo Freire. In: RUSCHEINSKY, Aloísio (org.). Educação Ambiental: abordagens múltiplas. Porto Alegre, RS: Artmed, 2002.

RUSCHEINSKY, Aloísio. As Rimas da ecopedagogia: uma perspectiva ambientalista. In: RUSCHEINSKY, Aloísio (org.). Educação Ambiental: abordagens múltiplas. Porto Alegre, RS: Artmed, 2002.

SILVA, Andiara; CANTARELLI, Roberta; NIEDERAUER, Priscila Dalla Porta. A Educação Ambiental como pressuposto de efetividade do Direito Humano Fundamental ao meio ambiente ecologicamente equilibrado. In: GORCZEVSKI, Clóvis (org.) Direitos Humanos Educação e Cidadania. Porto Alegre, RS: Ed. da UFRGS, 2007.

SIQUEIRA, Holgonsi Soares Gonçalves; PEREIRA, Maria Arleth. A interdisciplinaridade como superação da fragmentação. In: Caderno de Pesquisa: uma nova perspectiva sob a ótica da interdisciplinaridade. Santa Maria, RS, n. 68, set., 1995. 